Acta Hispanica (2018) 23: 315-323

\title{
DESDE JASENOVAC HASTA BUENOS AIRES: UN DESTINO DE DOS HERMANOS
}

\author{
ZOLTÁN BÁCS
}

Universidad del Servicio Público, Budapest

\begin{abstract}
Resumen: Dos de los hermanos Kálnai que emigraron a Argentina en 1920 jugaban un papel determinante en la arquitectura argentina hasta los años cuarenta. Esta obra se dedica a presentar la vida de los hermanos hasta su emigración.
\end{abstract}

Palabras clave: Jasenovac, Kaposvár, la Gran Guerra, Escuela Real Superior de Arquitectura, proyectos no realizados

\begin{abstract}
Two of the Kálnai brothers who emigrated to Argentina in 1920 had been playing an outstanding role in the architecture of this country up to the forties. This study is dedicated to present their life before their emigration.
\end{abstract}

Keywords: Jasenovac, Kaposvár, 1st World War, Royal College of Architecture, proyects without implementation

\section{Prefacio}

La historia de la Monarquía Austrohúngara y de sus minorías nacionales siempre ha sido y es un catauro de historias familiares trágicas, a veces cómicas, pero el rasgo común de estas historias es que sus protagonistas se vieron obligados a abandonar su país de nacimiento a consecuencia de disturbios políticos, económicos, sociales y militares. En el caso de Hungría estos disturbios cambiaron las fronteras del país disminuyendo su territorio a un tercio. Es decir, a veces no los ciudadanos abandonaron su país sino su país original les abandonó a ellos al cambiar las fronteras. Muchos de ellos sufrieron atrocidades por su nacionalidad y al fin y al cabo emigraron a otros países. Así vinieron a parar a Argentina muchas familias húngaras, entre ellas la de Antonio Balogh-Kovács. Nos conocimos en Buenos Aires en 2004. Él fue el presidente de la Cámara de Ingenieros Húngaros en Argentina y por eso hablabamos mucho sobre la arquitectura de la ciudad. Antonio me habló de un arquitecto húngaro, cuya influyencia se sentía hasta aquellos días del nuevo milenio. Este arquitecto fue Andrés Kálnay. Antonio me mostró varios edificios cerca de mi residencia en el barrio Belgrano, 
que fueron diseñados por Kálnay y me dijo que el antiguo Casino de la ciudad de Tigre en la Provincia de Buenos Aires también fue construido por él. Durante una de las excursiones a Tigre visité el antiguo Casino, actual Sala Municipal de Exposiciones. El edificio reflejaba enteramente la máxima minuciosidad del su arquitecto, sus altísimos valores artísticos, fantasía y capacidad de ubicar grandes espacios en edificios con tamaños limitados.

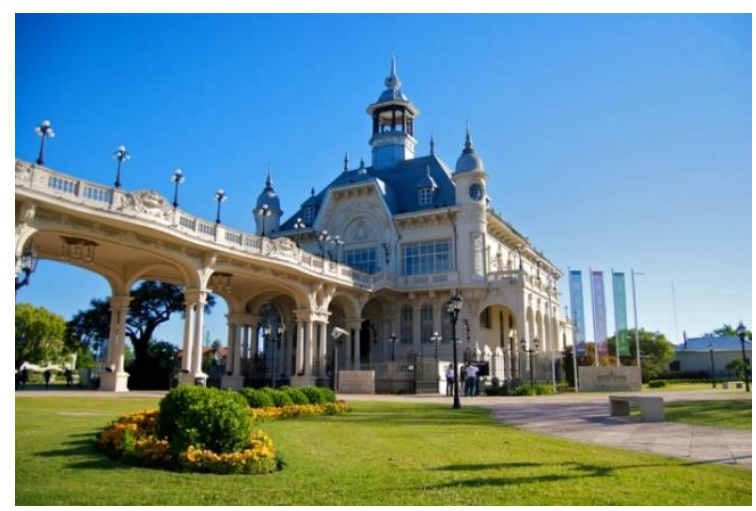

El antiguo Casino de Tigre, actual Museo Municipal de Arte de la ciudad http://www.nytimes.com/2010/11/28/travel/28tigre-overnighter.html

Un día Antonio me regaló el libro Andrés Kálnay un húngaro para la renovación arquitectónica argentina. Lo guardé bien en mi biblioteca hasta surgir la oportunidad de presentar el papel de los húngaros en el desarrollo de América Latina, más preciso de Argentina. ¿Cómo András Kálnai nacido en Jasenovac, actual Croacia, se convirtió en Andrés Kálnay, arquitecto que entre 1920 y 1940 determinaba las tendencias de la arquitectura argentina?

\section{Orígenes e infancia}

Todo empezó en 1893 en Jasenovac, una pequeña ciudad de aquel entonces en el Imperio Austrohúngaro, con una estación importante en la línea ferrorviaria que unía Budapest con Zagreb y con los balnearios marítimos. En este año, el 4 de abril nació András Kálnai, hijo del jefe de la estación ferrocarrilera, József Kálnai. Solo mucho más tarde, en el transcurso de mis investigaciones se aclaraba paso a paso cómo era la familia Kálnai. Ahora, después de más de un año de búsqueda ya hay algunos datos sobre su madre y hermanos, peor todavía no se sabe todo de la procedencia de la familia. La señora de Kálnai se llamaba Margit 
Rózsa. Antes de tener a András ya tenían un hijo, István y una hija, Bárbara. (István era mayor lo que se ve en las fotos familiares de la época de la Primera Guerra Mundial, en las cuales los hermanos aparecen todos en uniforme militar y István tiene el rostro más serio.) En total los Kálnai tenían siete hijos e hijas, István, András, György y Ferenc y Margit e Ilona. ${ }^{1}$

Los padres tal vez eran de la región. En el libro sobre András Kálnai se escribe que una tía suya vivía en Zagreb. Para aclarar los lazos familiares intenté buscar datos en los archivos de Jasenovac, pero la ciudad fue destruida dos veces en los últimos 80 años. Por primera vez en en año de 1941 cuando un campo de concentración fue construido en la ciudad para exterminar la población serbia y judía. A fines de la Segunda Guerra Mundial tanto el campo de concentración como la ciudad fueron enteramente arruinados junto con los archivos.

Hace unos 25 años durante las guerras en los Balcanes la ciudad de Jasenovac otra vez fue destruida y lo poco que quedó después de la Segunda Guerra Mundial desapareció definitivamente. Puesto que los Kálnai eran de origen judío intenté contactar con los archivos de la Comunidad Judía de Croacia en Zagreb, pero ellos tampoco tenían material sobre las comunidades en las pequeñas ciudades del fin del siglo XIX. Todavía queda pendiente si en los archivos de la Comunidad Judía de Osijek se puede encontrar algunos datos sobre los Kálnai o por lo menos sobre los judíos de Jasenovac. Solo para la comparación hay que tener en cuenta que la ciudad de Jasenovac actualmente tiene solo 700 habitantes.

\footnotetext{
${ }^{1}$ Sus datos biográficos conocidos parcialmente confirmados son: István Kálnay (Jasenovac, Croacia? - Budapest, 1980); Bárbara Kálnay (Jasenovac, Croacia, 1892 - Budapest, 2 de diciembre de 1944); Andrés (András) Kálnay (Jasenovac, Croacia, 4 de abril de 1893 Buenos Aires, 28 de diciembre de 1982); Jorge “Gyuri” Kálnay (Jasenovac, Croacia, 18 de mayo de 1894 - Buenos Aires, 13 de agosto de 1957); Ilona Kálnay (Jasenovac, Croacia? - Budapest, 4 de mayo de 1974); Margitka Kálnay (Jasenovac, Croacia? - Budapest, 1948); Ferenc "Francis" Kálnay (Koprivnica, Croacia, 18 de julio de 1900 - Carmel-bythe-Sea, Monterey County, California, EE. UU., 2 de diciembre de 1992).
} 
Desde Jasenovac hasta Buenos Aires: un destino de dos hermanos

\section{Años escolares}

Los primeros dos años los hermanos András y György los pasaron en la escuela de Jasenovac. Los Balcanes nunca eran una región de calma, sin tensiones por motivos étnicos y por eso los hermanos tenían fricciones con otros alumnos de sus clases de origen croata. Para evitar que estos conflictos estudiantiles se convirtieran en conflictos mayores y tuvieran consecuencias más graves, los padres enviaron a András y György a estudiar a Zagreb donde vivía una tía de ellos. Desafortunadamente los conflictos no se apaciguaron y por eso los hermanos fueron enviados a Kaposvár, a la escuela - internado para varones de la Compañía Ferroviaria Húngara (MÁV) para los años académicos 1901/1902 y 1902/1903. En este período su padre, József, ya era jefe de la estación ferrocarrilera en Koprivnica (Kapronca), a unos 20 kilómetros de la frontera, por eso era un asunto fácil vigilar la vida estudiantil de los muchachos.

Aquel entonces la compañía ferroviaria hungara era una de las mayores empresas estatales con un número muy elevado de empleados. Puesto que los empleados de la empresa trabajaban en diferentes ciudades y aldeas por todo el país que aque período tenía una extensión de casi 300 mil kilómetros cuadrados, la compañía trataba de aliviar los problemas de sus empleados en torno a la educación de sus hijos. Por eso instalaron escuelas - internados para los hijos de los ferrocarrileros en dos ciudades, en Kaposvár y en Szeged en 1896. Por su ubicación geográfica estas ciudades llegaron a ser centros de docencia de nivel medio. En ambos lugares la educación tenía un alto nivel y aceptaban a los esudiantes sin limitaciones por religión u otros criterios.

Después de dos años pasados en Kaposvár los hermanos Kálnai siguieron sus estudios en un centro docente muy celebre y tradicional en la ciudad de Csurgó. Este colegio fue fundado por la Iglesia Reformada en 1792 y tenía muy buena fama. La ciudad se encuentra a unos 20 kilómetros de Koprivnica, es decir la familia Kálnay vivía casi juntos. El ambiente y el nivel de la enseñanza en Csurgó jugaban un papel determinante en la vida de los hermanos Kálnai. András siendo mayor a un año se graduó un año antes que György y continuó sus estudios en la Escuela Real Superior de Arquitectura en Budapest entre 1907 y 1910 la que era el centro más moderno y avanzado de la arquitectura por aquel entonces donde se concentraban los mejores arquitectos, profesores y científicos cuya influencia arquitectónica hasta hoy se siente en los edificios de todas las ciudades de Hungría, construidos a fines del siglo XIX y a principios del siglo XX. 


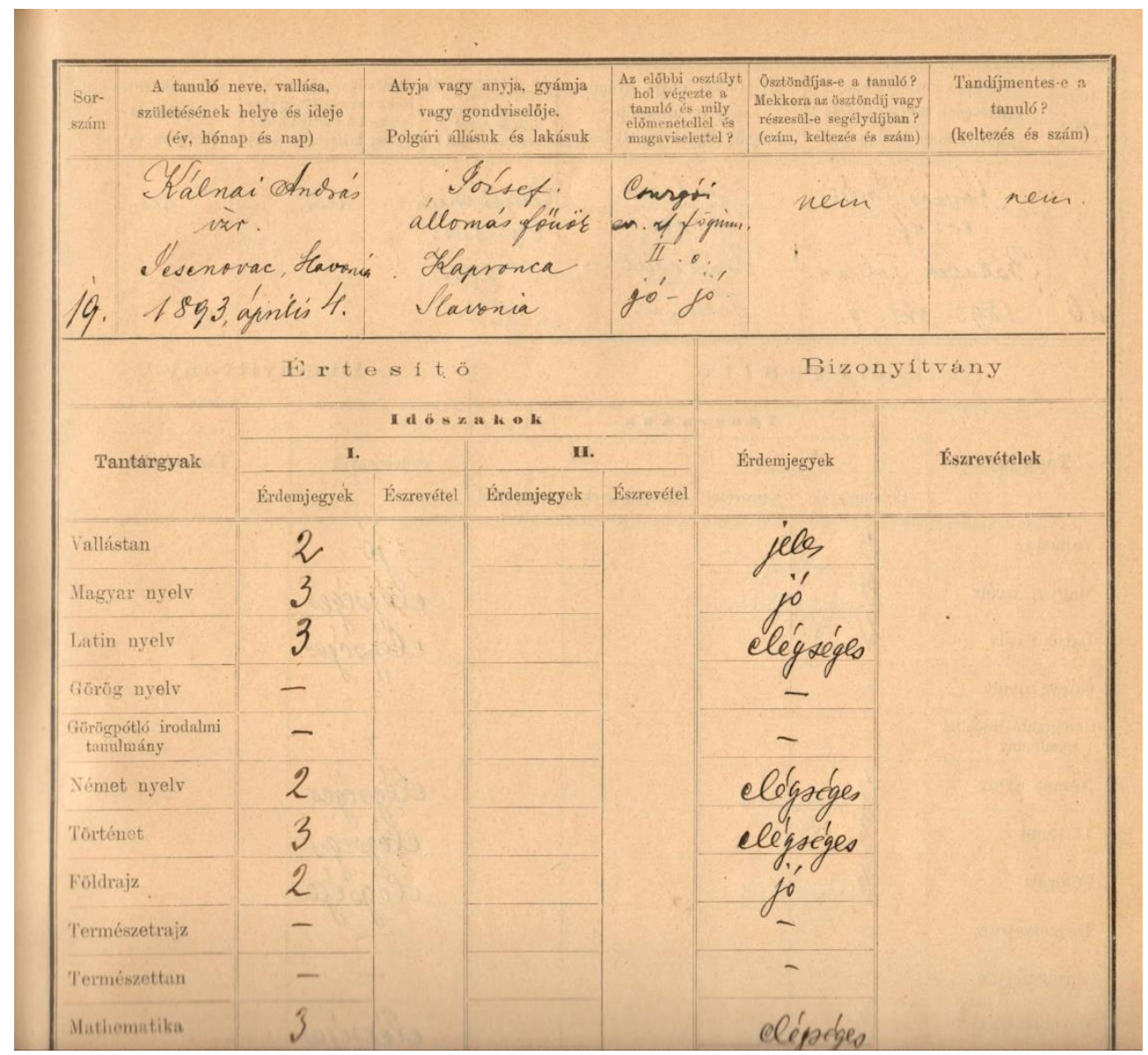

Fotografía de la matrícula de estudiante András Kálnai de la Escuela Real Superior de Arquitectura hecha por el autor

Durante las vacaciones András trabajaba en los talleres y estudios de los mejores arquitectos, tales como Manó Pollák, Oszkár Fritz, Ambrus Orth, Emil Somló, Dr. Arq. Dezső Hültl, Ödön Bleuer y la compañía Sugár \& Sajó. Esta preparación científica y práctica llegó a ser muy útil para él más tarde en Argentina. 
Desde Jasenovac hasta Buenos Aires: un destino de dos hermanos

\section{La Gran Guerra}

Pocas semanas después de que András cumpliera veintiún años él fue conscripto en el Ejército Austrohúngaro. Puesto que sabía de matemáticas y dibujaba bien le enviaron a Komárom a la Escuela de Artilleria de Campo. Yo traté de encontrar los documentos de sus estudios militares pero la formación de suboficiales había estado a cargo de divisiones u otras unidades de nivel superior y no a cargo de las Academias Militares, por eso mi búsqueda no dio resultados. Los documentos pudieron ser destrozados a fines de la Primera Guerra Mundial puesto que aquel entonces en los archivos militares de Viena guardaban solo los documentos de las unidades comunes y la unidad de artilleria donde servía el joven teniente András Kálnai se encontraba bajo mando húngaro. Después de la graduación András Kálnai se fue a Oradea (Nagyvárad) y sirvió en la Séptima Brigada del la Artilleria de Campo del Séptimo Cuerpo de Ejército. Recibió el rango del primer teniente en 1916. András Kálnai sufrió varias heridas ligeras en las campañas en Transilvania y fue condecorado con varias medallas.

Los hermanos de András -István, György y Ferenc- servían también en el ejército durante la guerra. Solo por falta de tiempo no pude encontrar documentos hasta ahora sobre su carrera militar en el Archivo Militar de Hungría.

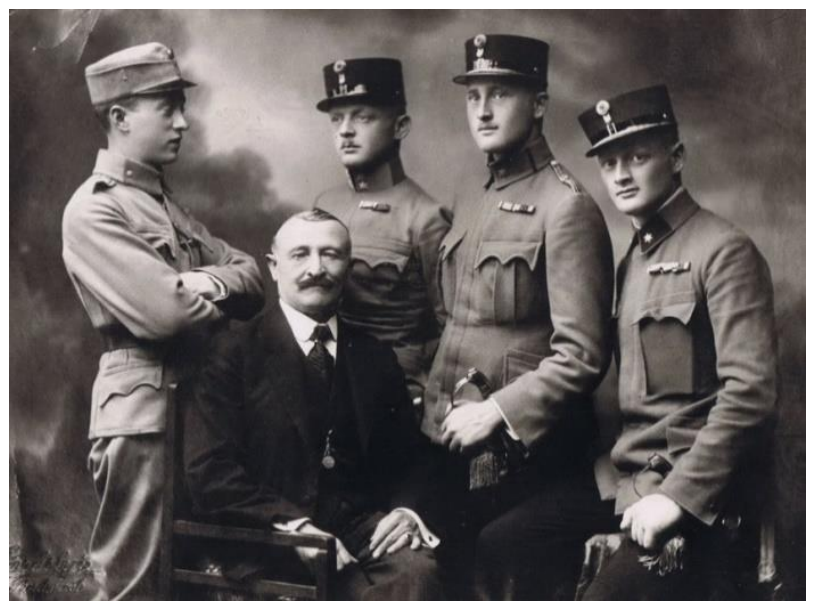

https://i2.wp.com/www.periodicodesdeboedo.com.ar/wpcontent/uploads/2011/12/hermanos-kalnay.jpg 


\section{Esperanzas y frustraciones}

József Kálnai, el padre de los hermanos, cuando se jubiló de la Compañía Ferroviaria en 1911, se trasladó a Budapest. Su vivienda se encontraba en la calle Kende, n. ${ }^{\circ} 14$. Después de terminar sus estudios, András y György abrieron su estudio en este apartamento pero no se figuraban como residentes. Desafortunadamente no hay otros datos sobre su lugar de residencia en la capital. Es muy probable que András y György después de la guerra regresaran a este estudio en la calle Kende y trataron de integrarse en la vida arquitectónica. Para eso, András obtuvo la licencia del ingeniero en 1919, es decir, ya tenía derecho no solo dirigir las obras de construcción sino tenía derecho a proyectar edificios. Los hermanos albergaban grandes esperanzas y expectaciones que la nueva República brindaría un gran desarrollo en la arquitectura también. Muy pronto aparecieron diferentes proyectos de construcción incluyendo las 48 habitaciones para los refugiados, pero por la falta de financiamiento estos proyectos no fueron realizados. Por lo menos entre los documentos del Archivo Municipal de Budapest no hay datos sobre su realización. Según la historia familiar András participó en la construcción de otro gran edificio en el centro de Budapest, en la actual plaza Széchenyi, al lado del puente de Cadenas. La compañía de seguros Generali tenía su sede cerca de este lugar y tenía intenciones de construir un edificio más grande para sus oficinas en la parte opuesta al edificio de la Academia de Ciencias. La verdad es que el nuevo edificio de Generali nunca fue construido y el edificio Lloyd que se encontraba enfrente de la Academia permanció allá hasta 1949 cuando después de la Segunda Guerra Mundial el edificio semidestruido fue destruido definitivamente para construir en este territorio un hotel en 1983. Estos planes frustrados tal vez jugaron un papel importante en la vida de András y György cuando decidieron emigrar.

Existe otra discrepancia entre las fuentes usadas durante la investigación. Según las fuentes familiares András se llevaba mal con los bolcheviques que llegaron al poder después de 21 de marzo de 1919 y eso sirvió de motivo para la emigración también. Otras fuentes dicen que durante el período cuestionado András llegó a ser uno de los dirigentes de una organización de arquitectos y por eso se vio obligado a emigrar después. Desafortunadamente no dispongo de documentos que pudieran confirmar una de estas posiciones. El único hecho es que los hermanos se fueron a Italia, hasta Nápoles donde embarcaron un barco que partía a América. La intención original de los hermanos como de muchos otros emigrantes de la época, era ir a los Estados Unidos y empezar allá una nueva vida. Algunas fuen- 
tes dicen que el barco cambió su rumbo en alta mar y así llegaron András y György a San Nicolás de Arroyos, a unos 230 kilómetros a noroeste de Buenos Aires el 15 de marzo de 1920.

\section{Epílogo}

Desde los años 1920 hasta los años 1940 los hermanos Kálnay -como escribían su apellido en ese período- desempeñaban un papel determinante en la arquitectura argentina. Primero trabajaban juntos en su estudio, más tarde se separaron y György -Jorge siguió trabajando en la arquitectura mientras András- Andrés se dedicaba a pintura. György murió en Buenos Aires en 1957.

Existe información no confirmada de que Andrés regresó a Hungría dos veces. Primero en 1934 como miembro de la delegación argentina que participó en el congreso de la Asociación de los Arquitectos Húngaros, y por última vez en 1968. Lo que se refiere a la primera visita los archivos de la Asociación se quemaron durante la Segunda Guerra Mundial y por eso cuando reorganizaron la asociación y establecieron un nuevo archivo, en esto no había materiales de los años anteriores a la guerra. La única referencia de esta visita se encuentra en el libro referido en el prefacio. Sobre la visita de Andrés Kálnay a Budapest en 1968 se puede leer solo en el artículo de Miklós Vincze (Kultúrák, 2015).

Los trabajos de los hermanos Kálnay en Argentina están muy bien documentados y son muy conocidos no solo por los arquitectos argentinos sino por el amplio público. Forman parte de la herencia cultural arquitectónica argentina del siglo XX de que este país tan lejano y cercano al mismo tiempo puede ser muy orgulloso.
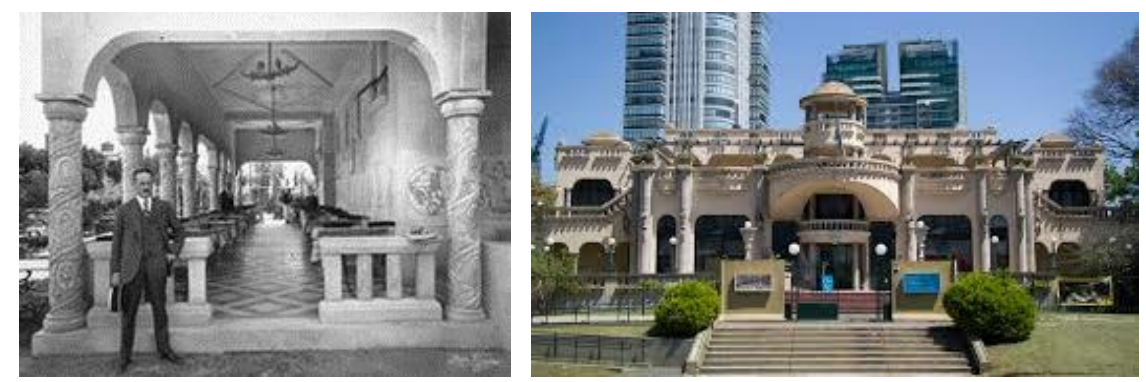

Andrés Kálnay frente a su obra la Cervecería Munich en Buenos Aires en 1929 y el mismo edificio hoy, Museo del Humor

https://es.wikipedia.org/wiki/Edificio_de_la_Cervecer\%C3\%ADa_Munich http://puertomaderodiario.com.ar/edificio-de-la-munich-mucho-mas-que-un-museo/ 
Zoltán Bács

\section{Bibliografía}

A.A.V.V. 2000. Andrés Kálnay. Un búngaro para la renovación arquitectónica argentina. Buenos Aires: Ediciones CEDODAL.

Balla, Tibor - Csikány, Tamás - Gulyás, Géza - Horváth, Csaba - Kovács, Vilmos. 2014. A magyar tüzérség 100 éve, 1913 - 2013. Budapest: Zrínyi Kiadó.

Bolla, Zoltán. 2016. A magyar art deco épitész̨et. Budapest: Publio Kiadó Kft.

Vasúti és Közlekedési Közlöny, 118/1893.

Vasúti és Közlekedési Közlöny, 32/1895.

Vince, Miklós. 2015. “A magyar testvérpár, akik örökre megváltoztatták az argentin főváros utcáit" Kultúrák és Cool Túrák, 05-15-2015. Fecha de consulta: 21 de marzo de 2017. Asequible en: http://24.hu/kozelet/2015/10/05/amagyar-testverpar-akik-orokre-megvaltoztattak-az-argentin-fovaros-utcait/ 